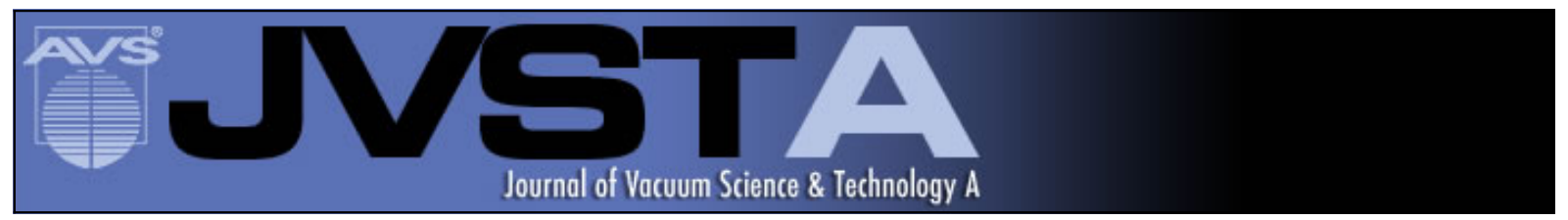

\title{
Processing of PbTiO3 thin films. I. In situ investigation of formation kinetics
}

Chen C. Li and Seshu B. Desu

Citation: Journal of Vacuum Science \& Technology A 14, 1 (1996); doi: 10.1116/1.579919

View online: http://dx.doi.org/10.1116/1.579919

View Table of Contents: http://scitation.aip.org/content/avs/journal/jvsta/14/1 ?ver=pdfcov

Published by the AVS: Science \& Technology of Materials, Interfaces, and Processing

Articles you may be interested in

Xray photoelectron spectroscopy study on composition and structure of solgel derived $\mathrm{PbTiO} 3$ thin films J. Appl. Phys. 80, 202 (1996); 10.1063/1.362805

caxis oriented ferroelectric thin films of $\mathrm{PbTiO} 3$ on $\mathrm{Si}$ by pulsed laser ablation

Appl. Phys. Lett. 68, 1582 (1996); 10.1063/1.116687

Processing of $\mathrm{PbTiO} 3$ thin films. III. Effects of ion bombardment

J. Vac. Sci. Technol. A 14, 13 (1996); 10.1116/1.579910

Processing of $\mathrm{PbTiO} 3$ thin films. II. In situ investigation of stress relaxation

J. Vac. Sci. Technol. A 14, 7 (1996); 10.1116/1.579883

Difference Raman spectra of $\mathrm{PbTiO} 3$ thin films grown by metalorganic chemical vapor deposition Appl. Phys. Lett. 62, 349 (1993); 10.1063/1.108954
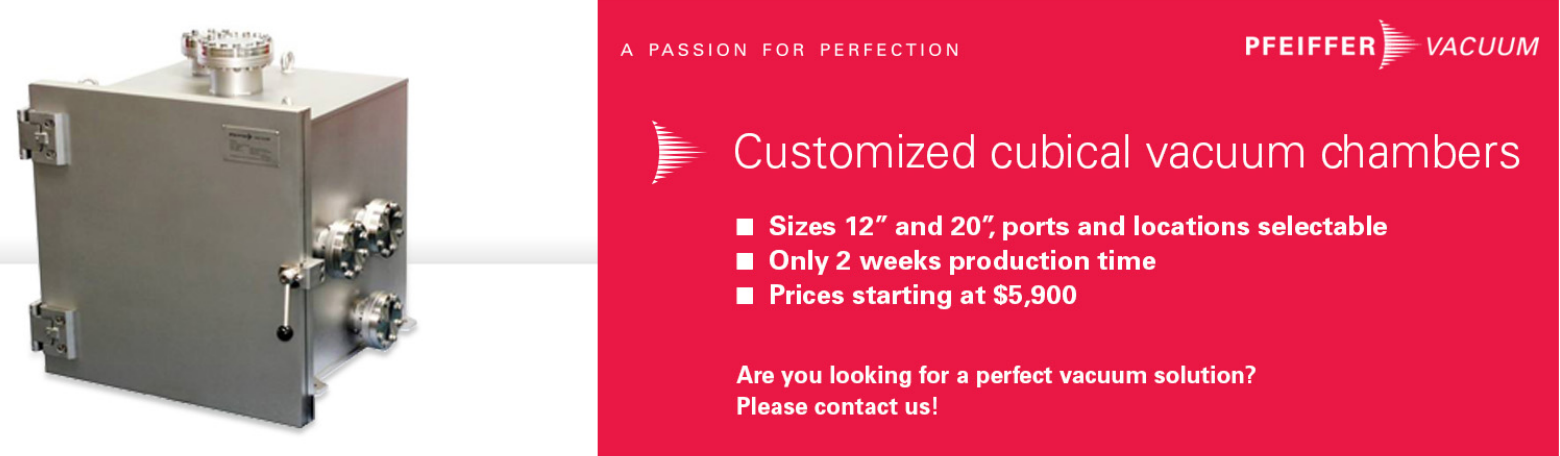


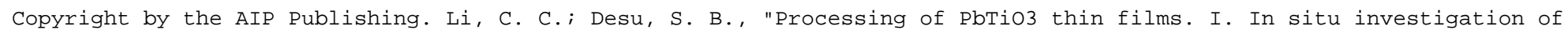
formation kinetics," J. Vac. Sci. Technol. A 14, 1 (1996); http://dx.doi.org/10.1116/1.579919

\title{
Processing of $\mathrm{PbTiO}_{3}$ thin films. I. In situ investigation of formation kinetics
}

\author{
Chen C. Li and Seshu B. Desu ${ }^{\mathrm{a})}$ \\ Department of Materials Science and Engineering, Virginia Polytechnic Institute and State University, \\ Blacksburg, Virginia 24061
}

(Received 28 July 1994; accepted 7 October 1995)

\begin{abstract}
A novel in situ stress measurement technique to study the formation kinetics of multicomponent oxide thin films was developed and was applied to $\mathrm{PbTiO}_{3}$. Single phase $\mathrm{PbTiO}_{3}$ thin films were formed from the reaction between films in the deposited $\mathrm{PbO} / \mathrm{TiO}_{2}$ multilayer. The film stoichiometry was accurately controlled by depositing individual layers with the required thickness. The development of film stresses associated with the formation of the product layer at the $\mathrm{PbO} / \mathrm{TiO}{ }_{2}$ interface of the multilayers was used to monitor the growth rate of the $\mathrm{PbTiO}_{3}$ layer. It was found that growth of the $\mathrm{PbTiO}_{3}$ phase obeyed the parabolic law, and the effective activation energy was estimated to be $108 \mathrm{~kJ} / \mathrm{mole}$. It is believed that the mechanism of this reaction was dominated by grain boundary diffusion of the participating cations. (c) 1996 American Vacuum Society.
\end{abstract}

\section{INTRODUCTION}

Thin films of multicomponent oxides such as $\mathrm{PbTiO}_{3}$ have been extensively studied because of their remarkable ferroelectric, pyroelectric, and piezoelectric properties. The applications of these thin films include optoelectronic devices, sensors, transducers, and nonvolatile memory devices. ${ }^{1}$ A variety of vapor deposition techniques have been applied to the fabrication of these thin films. Physical vapor deposition techniques such as sputtering and evaporation often encounter problems in controlling film stoichiometry. One way to overcome this problem is the use of the multilayer approach, ${ }^{2}$ in which the composition of the films is accurately controlled by depositing the required thickness for individual layers (e.g., $\mathrm{A}+\mathrm{B} \rightarrow \mathrm{AB}$ ). For $\mathrm{PbTiO}_{3}$ system, either metallic,

$$
\mathrm{Pb}+\mathrm{Ti} \rightarrow \mathrm{PbTiO}_{3},
$$

or oxide multilayers,

$$
\mathrm{PbO}+\mathrm{TiO} \rightarrow \mathrm{PbO}+\mathrm{TiO}_{2} \rightarrow \mathrm{PbTiO}_{3}
$$

can be used to obtain the compound.

In order to optimize the process of thin film fabrication, it is of great importance to understand the formation kinetics. When a thin film, A, is deposited on a substrate, the total film stress of film A can be a function of temperature, time, substrate, and film thickness. ${ }^{3}$ If a second film, B, is deposited on top of $\mathrm{A}$, the total film stress of this bilayer can be influenced not only by the aforementioned factors but also by interaction between $\mathrm{A}$ and $\mathrm{B}$. Let us assume that the film stresses of individual layers are constant at a given temperature, and that a product layer of $\mathrm{AB}$ is formed at the interface between $\mathrm{A}$ and $\mathrm{B}$, then the total stress of the multilayer will be influenced by the thickness of the AB film. Since the extent of reaction is time dependent at a given temperature, the total stress of the multilayer is also time dependent.

a) Author to whom correspondence should be addressed.
Therefore, the formation kinetics of multicomponent thin films can be studied by using the in situ stress measurement technique.

The in situ stress measurement technique was applied by Apblett et al. on a $\mathrm{Cu} / \mathrm{Ti}$ multilayer alloy system. ${ }^{4}$ In their study, the origin of these stresses was attributed to the formation of compounds such as $\mathrm{TiCu}$ and $\mathrm{TiCu}_{3}$. The formation of $\mathrm{TiCu}$ resulted in compressive stresses and $\mathrm{TiCu}_{3}$ resulted in tensile stresses. However, neither semiquantitative nor quantitative relations between total stress and reaction kinetics have been documented. In addition, the unavoidable phenomenon of stress relaxation in thin films was not discussed either.

In this article, we demonstrate the use of the in situ stress measurement technique for studying the formation kinetics of $\mathrm{PbTiO}_{3}$ from $\mathrm{PbO} / \mathrm{TiO}_{2}$ multilayers. Our kinetic data matched very well with the reported data obtained for the $\mathrm{PbO}$ and $\mathrm{TiO}_{2}$ powder mixtures. Using this technique, the grain boundary diffusion coefficient was deduced. In Part II we will discuss the phenomenon of stress relaxation in $\mathrm{PbTiO}_{3}$ thin films.

\section{METHODOLOGY}

The formation of $\mathrm{PbTiO}_{3}$ thin films takes place via the reaction between $\mathrm{PbO}$ and $\mathrm{TiO}_{2}$ films. The reaction product separates the reactants from one another, and the reaction proceeds by diffusion of the participating components through the reaction product. For very low solubilities of the reactants in the reaction product (i.e., for a product with a very low range of homogeneity, as shown in the $\mathrm{PbO}-\mathrm{TiO}_{2}$ phase diagram ${ }^{5}$ ) the particle fluxes are locally constant and, as long as local thermodynamic equilibrium is maintained at the phase boundary, a planar growth mode is made possible and a parabolic growth law results.

When sequentially deposited films are all very thin compared to the substrate, each film imposes a separate bending moment and separate curvature. Since moments are additive, so are the curvatures. 


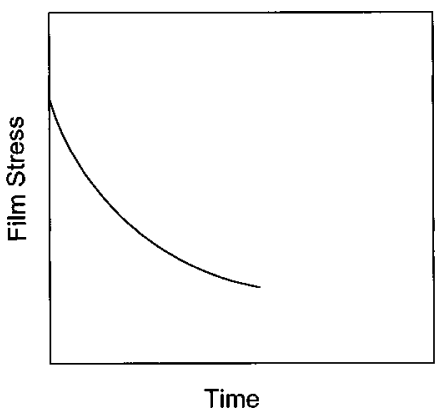

FIG. 1. Schematic stress-time plot for $\mathrm{PbTiO}_{3}$ thin film reaction.

$1 / R_{1}+1 / R_{2}+\cdots=\left(1-\nu_{s} / E_{s}\right)\left(6 / d_{s}^{2}\right)\left(\sigma_{1} d_{1}+\sigma_{2} d_{2}+\cdots\right)$,

$\sigma d=\sum \sigma_{i} d_{i}, \quad i=1$ to $n$,

where $R_{i}$ denotes the radius of curvature of the layer $i, \nu_{s}$ and $E_{s}$ are the elastic constants of the substrate, and $\sigma$ and $d$ denote total film stress and thickness, respectively.

For a $\mathrm{PbO} / \mathrm{TiO}_{2}$ multilayer on a sapphire substrate, the total film stress can be expressed as

$\sigma d_{a b}=\sigma_{a} d_{a}+\sigma_{b} d_{b}$,

where $\left({ }_{a}\right)$ and $\left({ }_{b}\right)$ denote $\mathrm{PbO}$ and $\mathrm{TiO}_{2}$ and later $\left({ }_{a b}\right)$ is $\mathrm{PbTiO}_{3}$.

Assuming that (i) stresses of the $\mathrm{PbO}, \mathrm{TiO}_{2}$, and $\mathrm{PbTiO}_{3}$ layers $\left(\sigma_{a}, \sigma_{b}\right.$, and $\left.\sigma_{a b}\right)$ are constant during the formation of $\mathrm{PbTiO}_{3}$, (ii) the total thickness $(d)$ of the multilayer is constant, and (iii) initial stress is defined as $\sigma_{i}=\left(\sigma_{a} d_{a}+\sigma_{b} d_{b}\right) / d$, where $d_{a} / d_{b} \sim 2 / 1$, this ratio is close to the ratio of density of the participating materials. Accordingly, the consumption of the $\mathrm{PbO}$ layer should be twice as fast as that of the $\mathrm{TiO}_{2}$ layer. The value of $\sigma_{i}$ is obtained from the stress-temperature plot where the temperature is $500{ }^{\circ} \mathrm{C}$, which will be explained later in this article.

At a certain fraction of reaction where a layer of $\mathrm{PbTiO}_{3}$ $\left(d_{a b}\right)$ is formed, the total film stress becomes [using Eq. (5) and the relation $\left.d_{a} / d_{b} \sim 2 / 1\right]$ :

$$
\begin{aligned}
\sigma d & =\left\{\sigma_{a}\left[d_{a}-(2 / 3) d_{a b}\right]+\sigma_{b}\left[d_{b}-(1 / 3) d_{a b}\right]+\sigma_{a b} d_{a b}\right\}, \\
\sigma & =(1 / d)\left\{\left(\sigma_{a} d_{a}+\sigma_{b} d_{b}\right)+d_{a b}\left[\sigma_{a b}-\left(2 \sigma_{a}+\sigma_{b}\right) / 3\right]\right\} \\
& =\left[\left(\sigma_{a} d_{a}+\sigma_{b} d_{b}\right) / d\right]+\left[\sigma_{a b}-\left(2 \sigma_{a}+\sigma_{b}\right) / 3\right]\left(d_{a b} / d\right) \\
& =\sigma_{i}+\left(\sigma_{a b}-\sigma_{i}\right)\left(d_{a b} / d\right) .
\end{aligned}
$$

Therefore,

$$
d_{a b} / d=\left(\sigma-\sigma_{i}\right) /\left(\sigma_{a b}-\sigma_{i}\right)=f(T, t) .
$$

From Eq. (6) and the parabolic law, the film stress-time relationship can be plotted as shown in Fig. 1.

\section{EXPERIMENTAL PROCEDURE}

The film deposition system was a conventional cryopumped electron beam evaporator. The 2 in. sapphire substrates were mounted $34 \mathrm{~cm}$ above the electron beam evaporation source. Before deposition, the system was pumped down to $4 \times 10^{-8}$ Torr, rising to $2-3 \times 10^{-7}$ Torr during depo-

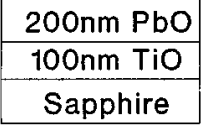

FIG. 2. Configuration of the multilayer.

sition. All the depositions were performed at ambient temperature with a deposition rate of $0.2-0.5 \mathrm{~nm} / \mathrm{s}$. Total film thickness was kept constant at $300 \mathrm{~nm}$.

High purity, vapor deposition grade oxides ( $\mathrm{PbO}$ and $\mathrm{TiO})$ were used as the evaporation sources. $\mathrm{TiO}_{2}$ was not used due to its decomposition during deposition. Based on theoretical calculations and taking into account the loss of $\mathrm{Pb}(10 \mathrm{~mol} \%$ of $\mathrm{PbO}$ was added), the thickness of the $\mathrm{PbO}$ and $\mathrm{TiO}$ layers was approximately 200 and $100 \mathrm{~nm}$, respectively. The configuration of the multilayer is shown in Fig. 2. The substrates were cleaned by a series of organic solutions and de-ionized water, followed by drying in $\mathrm{N}_{2}$ gas.

Film stress measurements as a function of temperature and time were performed for the $\mathrm{PbO} / \mathrm{TiO}$ oxide multilayers, on 2 in.-diam sapphire substrates in air. The heating rate was $5{ }^{\circ} \mathrm{C} / \mathrm{min}$. The sample curvature was calculated from the change in position of a reflected laser beam. The position was measured by a position sensitive detector while the beam was scanned across the sample. The total film stress was calculated by comparing the substrate curvature before and after film deposition using Stoney's Equation, ${ }^{6}$ which yields the biaxial stress in the thin films parallel to the substrate:

$$
\sigma=\left[E_{s} / 6\left(1-\nu_{s}\right)\right]\left(t_{s}^{2} / t_{f}\right)(1 / R),
$$

where $E_{s}, \nu_{s}$, and $t_{s}$ are Young's modulus, the Poisson ratio, and the thickness of the substrate, respectively, and $t_{f}$ is the film thickness. $R$ is an effective radius of curvature of the substrate determined by $R=1 /\left(1 / R_{2}-1 / R_{1}\right)$, where $R_{1}$ and $R_{2}$ are the substrate radii of the curvature before and after film deposition. This formula is applicable when $t_{f}$ is far smaller than $t_{s}$ and the central wafer deflection is much smaller than the diameter of the wafer. Both conditions are met in the present work.

Based on this technique, stress-temperature and stresstime plots of the $\mathrm{PbO} / \mathrm{TiO} /$ sapphire specimens were obtained. In order to quantify the extent of the reaction and the morphological change associated with film stress development, separate tests such as x-ray diffraction analysis for phase determination and scanning electron microscopy for morphology observation were carried out.

\section{RESULTS AND DISCUSSION}

Electron spectroscopy for chemical analysis (ESCA) of as-deposited individual $\mathrm{PbO}$ and $\mathrm{TiO}$ layers indicated that $\mathrm{Pb}: \mathrm{O}$ and Ti:O ratios are near unity (1.03 for $\mathrm{PbO}$ and 1.0 for TiO). A similar analysis was also carried out for the films subjected to annealing at temperatures lower than $500{ }^{\circ} \mathrm{C}$. The $\mathrm{Pb}: \mathrm{O}$ ratio quickly became 1:1 upon heating, whereas the Ti:O ratio gradually reached $1: 2$ in the temperature range 


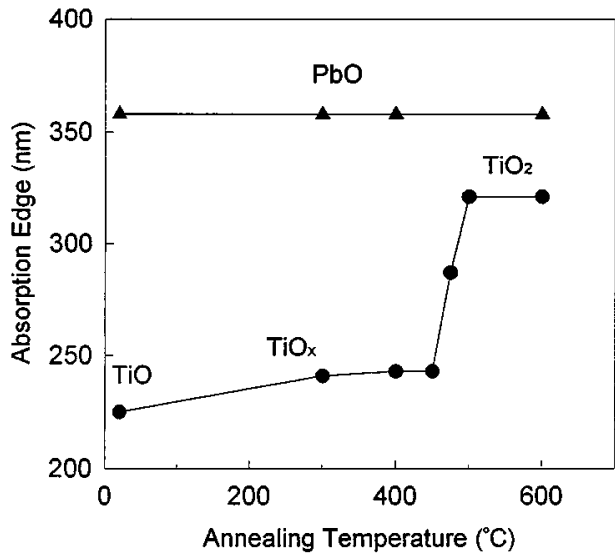

Fig. 3. Absorption edge of $\mathrm{PbO}$ and $\mathrm{TiO}_{x}$ films as a function of temperature.

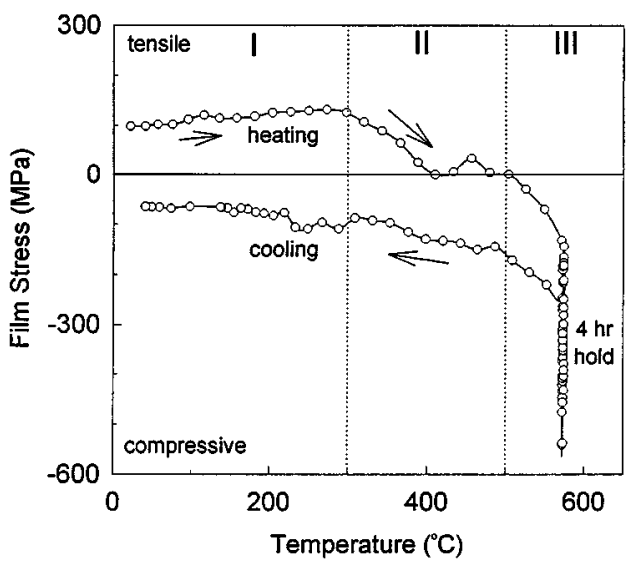

FIG. 4. A typical film stress-temperature plot during formation of a $\mathrm{PbTiO}_{3}$ thin film.

stress did not change much, as shown in region I. The tensile stresses in the film decreased as the curve entered region II at around $300{ }^{\circ} \mathrm{C}$ and reached a local minimum at around $400{ }^{\circ} \mathrm{C}$; it then increased slightly and decreased to a state where the film was nearly stress free at $500{ }^{\circ} \mathrm{C}$. The stress development in region II was attributed to the oxidation of $\mathrm{TiO}$ to $\mathrm{TiO}_{2}$. This was confirmed by a separate study which showed that the stress of an individual $\mathrm{PbO}$ layer remained constant throughout the temperature range examined. The intake of oxygen into the films could result in increased film volume, thereby generating compressive stresses. A reasonable explanation for the local stress surge at around $450{ }^{\circ} \mathrm{C}$ is that it is due to crystallization in the titanium oxide layer which generates tensile stress. In region III, the stresstemperature curve fell entirely into the compressive state. Compressive stress continued developing in the films when the temperature was above $500{ }^{\circ} \mathrm{C}$ and reached a local minimum in the isothermal region; then the tensile stress started building up. This region of the curve was attributed to the formation of the $\mathrm{PbTiO}_{3}$ phase in the film and to stress relaxation.

Film stress during cooling showed very good linearity only against temperature. Therefore thermal stress $\left(\sigma_{\mathrm{th}}\right)$ could be calculated as

$$
\sigma_{\mathrm{th}}=\left(E_{f} / 1-\nu_{f}\right)\left(1 \alpha_{f}-\alpha_{s}\right)\left(T_{a}-T\right)
$$

where $T_{a}$ is the annealing temperature, $E_{f} /\left(1-\nu_{f}\right)$ is the biaxial modulus of the $\mathrm{PbTiO}_{3}$ film, and $\alpha_{f}$ and $\alpha_{s}$ are thermal expansion coefficients of the film and substrate. Taking the $\alpha_{s}$ of sapphire as $8.8 \times 10^{-6} /{ }^{\circ} \mathrm{C},{ }^{8}$ the thermal expansion coefficient of the $\mathrm{PbTiO}_{3}$ film was calculated as $10.6 \times 10^{-6} /{ }^{\circ} \mathrm{C}$. This value was found to be higher than that of $7.1 \times 10^{-6} /{ }^{\circ} \mathrm{C}$ for $\mathrm{PbTiO}_{3}$ ceramics, ${ }^{9}$ which is considered to be stress free in the temperature range below Curie point.

With increasing temperature, the interaction between the lead oxide and the titanium oxide layers is depicted schematically in Fig. 5. In region III, stress development involves two kinetic processes, $\mathrm{PbTiO}_{3}$ formation and stress relax- 


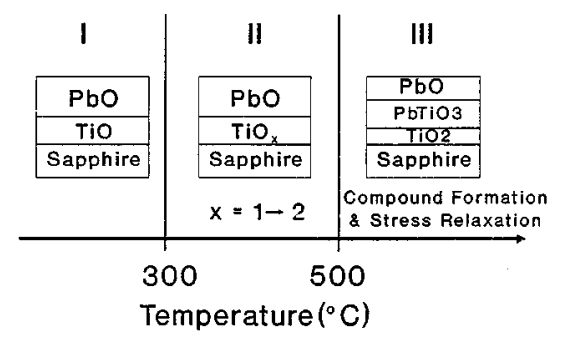

FIG. 5. Interaction between $\mathrm{PbO}$ and $\mathrm{TiO}_{x}$ layers as a function of temperature.

ation. In this article, the authors try to establish a basic understanding of the kinetics of $\mathrm{PbTiO}_{3}$ formation only using the in situ stress measurement technique. From this point on this article concentrates on the temperature regime from 550 to $625^{\circ} \mathrm{C}$.

The isothermal region for several different annealing temperatures was replotted in Fig. 6. The development of compressive stress in the early stage of the stress-time plots can be attributed to the growth of the $\mathrm{PbTiO}_{3}$ layer. During the growth process, the absorption of vacancies from a free surface by the product layer can bring about a compressive stress because of "swelling" of the deposit. As the growth process was completed, the film stress reached an extreme, that is, the local minima in the plots as shown in Fig. 6.

Using this in situ stress measurement technique, one can monitor the kinetics of compound formation step by step even if the reaction is reasonably fast. For instance, the minimum was found at around $40 \mathrm{~min}$ for $575^{\circ} \mathrm{C}$. Lowering the annealing temperature increased the time to achieve a minimum, e.g., around $100 \mathrm{~min}$ for $550^{\circ} \mathrm{C}$. Conversely, raising the annealing temperature decreased the time to achieve a minimum, e.g., around $20 \mathrm{~min}$ for $600{ }^{\circ} \mathrm{C}$. By annealing at $625^{\circ} \mathrm{C}$, the minimum occurred too fast to appear on the plot.

Intuitively, the stress plots (Fig. 6) can be divided into two different regions as shown in Fig. 7. The asymmetry of the curve implied two different mechanisms for the two distinct regions. During formation, a large amount of vacancies and grain boundaries were generated. Accordingly, the strain en-

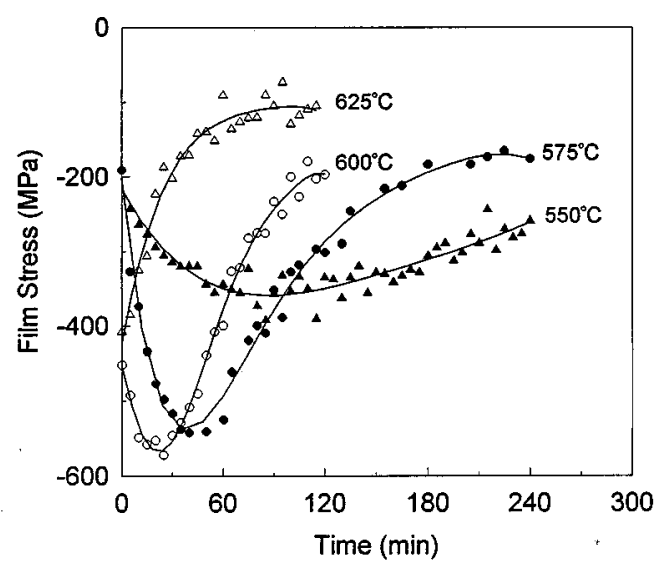

FIG. 6. Stress-time plots for $\mathrm{PbTiO}_{3}$ thin films.

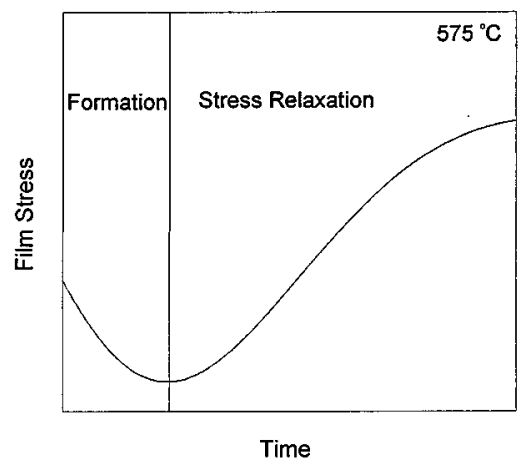

FIG. 7. Implications in a stress-time plot.

ergy stored in the vacancies and grain boundaries needed to be released. Tensile stress was generated by the elimination of vacancies and grain boundaries, therefore, film stress relaxed.

\section{B. Formation kinetics}

Figure 8 shows the fraction of the $\mathrm{PbTiO}_{3}$ formation, $f$, determined using $\mathrm{x}$-ray diffraction as a function of annealing time for the temperature ranging from 550 to $600{ }^{\circ} \mathrm{C}$. From Fig. 8 the thickness of the $\mathrm{PbTiO}_{3}$ layer formed can be deduced using

$$
d_{a b}=(d) .(f) .
$$

The growth of the $\mathrm{PbTiO}_{3}$ layer is governed by the parabolic law, i.e.,

$$
\left(d_{a b}\right)^{2}=k t,
$$

where $k$ is the rate constant. Figure 9 illustrates the kinetics of $\mathrm{PbTiO}_{3}$ growth for three different temperatures. Since the data of Fig. 8 represent a diffusion-controlled growth process, the chemical interdiffusion coefficient $(D)$ can be determined from the rate constant $k=4 D$. The rate constant, $k$, has an Arrhenius behavior as shown in Fig. 10. The straight line fit points to a thermally activated growth of $\mathrm{PbTiO}_{3}$ on

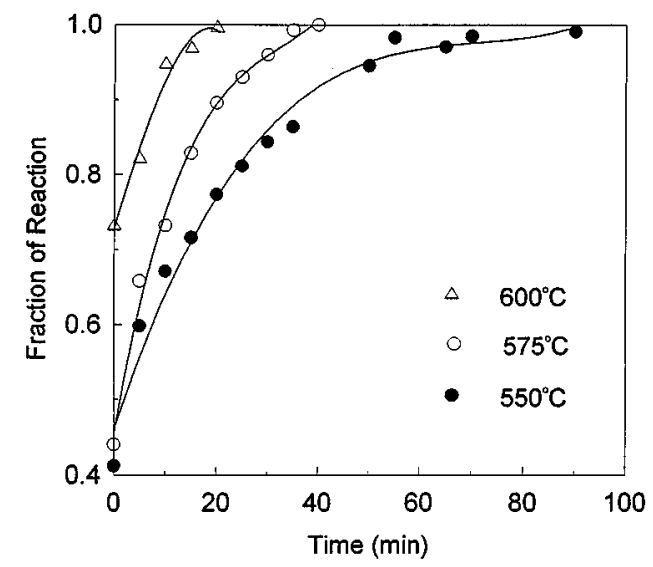

FIG. 8. Fraction of $\mathrm{PbTiO}_{3}$ formed as a function of time as determined by the $\mathrm{x}$-ray diffraction technique. 


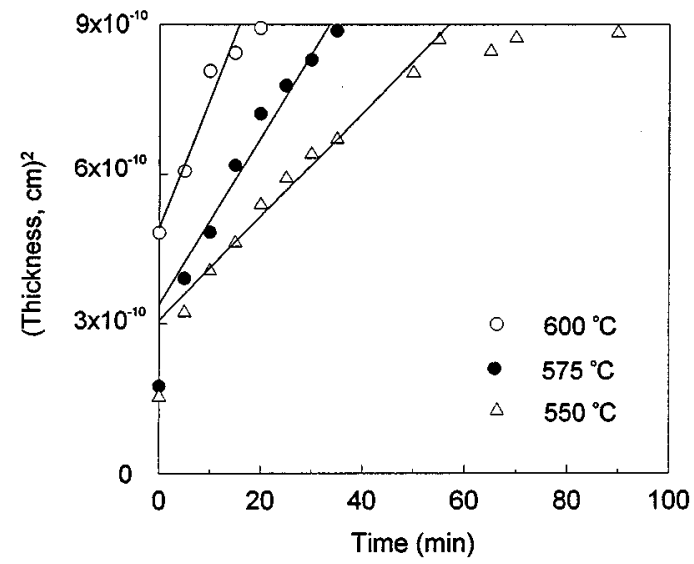

FIG. 9. Time dependence of the thickness of $\mathrm{PbTiO}_{3}$ films.

sapphire. The activation was estimated to be $108 \mathrm{~kJ} / \mathrm{mole}$. This value is in excellent agreement with the literature values as shown in Table I.

\section{Mechanism of $\mathrm{PbTiO}_{3}$ formation}

From $\mathrm{PbO}$ and $\mathrm{TiO}_{2}$ layers, a polycrystalline $\mathrm{PbTiO}_{3}$ phase is formed. During reaction, the fluxes of the components in the product layer, which are responsible for the advancement of the reaction, are the moving ions. Therefore, in order to preserve local electrical neutrality, the fluxes of the different ions must always be coupled with each other. Consequently, the following combinations are possible: either oppositely charged ions flow in the same direction, or ions with like charges flow in opposite directions through the reaction product. These simple considerations give the possible limiting cases of a solid state reaction between ionic crystals. For the formation of ionic crystals such as $\mathrm{PbTiO}_{3}$, it is the slower partner that essentially determines the reaction rate. From the rate constants, the chemical diffusion constant of $\mathrm{PbTiO}_{3}$ formation in this work could be calculated as $6.8 \times 10^{-14} \mathrm{~cm}^{2} / \mathrm{s}$ at $575^{\circ} \mathrm{C}$. The chemical diffusion constants at this temperature were estimated to be $1 \times 10^{-12}$ $\mathrm{cm}^{2} / \mathrm{s}$ for $\mathrm{PbO}$ (Ref. 13) and $7.4 \times 10^{-16} \mathrm{~cm}^{2} / \mathrm{s}$ for $\mathrm{TiO}_{2} \cdot{ }^{13}$

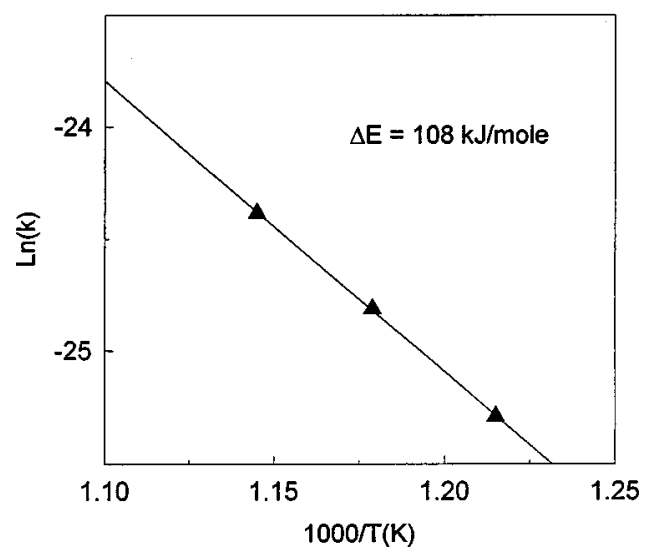

FIG. 10. The Arrhenius behavior of rate constants of $\mathrm{PbTiO}_{3}$ formation.
TABLE I. Kinetic data of $\mathrm{PbTiO}_{3}$ formation.

\begin{tabular}{ccc}
\hline \hline $\begin{array}{c}\text { Activation energy } \\
(\mathrm{kJ} / \text { mole })\end{array}$ & Reference & Process \\
\hline $\mathbf{1 0 8}, 122$ & 7 & $\mathrm{PbO}+\mathrm{TiO}_{2}$ powders \\
151 & 10 & $\mathrm{~Pb}+\mathrm{TiO}_{2}$ powders \\
77 & 11 & $\mathrm{~Pb}(\mathrm{OH})_{2}+\mathrm{Ti}(\mathrm{OH})_{4}$ \\
& & $\mathrm{PbCO}_{3}+\mathrm{Ti}(\mathrm{OH})_{4}$ \\
81,69 & 12 & $\mathrm{TiO}_{2} \times n \mathrm{H}_{2} \mathrm{O}+\mathrm{PbCO}_{3} \times n \mathrm{H}_{2} \mathrm{O}$ \\
$\mathbf{1 0 8}$ & This work $(1993)$ & $\mathrm{PbO} / \mathrm{TiO}_{2}$ thin films \\
\hline \hline
\end{tabular}

Our experimental value is approximately an order lower than that for $\mathrm{PbO}$ and two orders higher than that for $\mathrm{TiO}_{2}$. This could suggest that transport of $\mathrm{Ti}^{4+}$ ions through the product layer is the rate-determining step. Furthermore, it is believed that the participating components diffuse mainly through grain boundaries. It is then reasonable to write the grainboundary diffusion constant as

$$
D_{\mathrm{gb}}=3 \times 10^{-7} \exp (-108000 / \mathrm{kT}) \mathrm{cm}^{2} / \mathrm{s} .
$$

It is well known that the effect of compressive stress on atomic or molecular diffusion in a constrained solid is to reduce the diffusivity because of the enhancement of steric hindrance in the lattice. ${ }^{14}$ Therefore, one can expect a lower grain boundary diffusion constant for a stress-free $\mathrm{PbTiO}_{3}$ formation.

From Eq. (12), one can extrapolate the rate constant of the $\mathrm{PbTiO}_{3}$ formation at $500{ }^{\circ} \mathrm{C}$. The amount of reaction between $\mathrm{PbO}$ and $\mathrm{TiO}_{2}$ films annealed at $500{ }^{\circ} \mathrm{C}$ for $0.1 \mathrm{~min}$ was calculated to be $2 \%$. This is self-consistent with the assumptions.

\section{SUMMARY}

A novel in situ stress measurement technique has been successfully developed to study the formation kinetics of multicomponent thin films such as $\mathrm{PbTiO}_{3}$. Using the multilayer approach, film composition can be simply controlled by the thickness of the individual layers. The formation of the $\mathrm{PbTiO}_{3}$ layer at the interface of $\mathrm{PbO} / \mathrm{TiO}_{2}$ altered the total stress of the multilayers. By monitoring stress changes in the multilayers, the in situ formation kinetics of $\mathrm{PbTiO}_{3}$ film was successfully examined and quantitatively documented. The activation energy of $\mathrm{PbTiO}_{3}$ formation was estimated to be $108 \mathrm{~kJ} /$ mole which is in excellent agreement with the value in the literature. It is believed that the formation of the $\mathrm{PbTiO}_{3}$ phase was dominated by the grainboundary diffusion mechanism because of the very fine grain size in the films. The grain-boundary diffusivity responsible for this reaction was also deduced.

\section{ACKNOWLEDGMENTS}

This work was financially supported by the Defense Advanced Research Agency (DARPA) through a project from the Office of Naval Research, and by The Center for Advanced Ceramic Materials at Virginia Tech. 
${ }^{1}$ M. Okuyama and Y. Hamakawa, Int. J. Eng. Sci. 29, 391 (1991).

${ }^{2}$ E. R. Myers and A. I. Kingon, Materials Research Society Symposium Proceedings (Materials Research Society, Pittsburgh, PA, 1990), Vol. 200.

${ }^{3}$ J. C. Braveman, W. D. Nix, D. M. Barnett, and D. A. Smith, Materials Research Society Symposium Proceedings (Materials Research Society, Pittsburgh, PA, 1989), Vol. 130.

${ }^{4}$ C. A. Apblett and P. J. Ficalora, Mater. Res. Soc. Symp. Proc. 239, 99 (1992).

${ }^{5}$ R. L. Holman, Ferroelectrics 14, 675 (1976).

${ }^{6}$ G. C. Stoney, Proc. R. Soc. London Ser. A 82, 172 (1909).

${ }^{7}$ G. Janson, E. Z. Friedenfelds, I. Skomorokha, and O. S. Maksimova, Uch. Zap. Rizh. Politekh. Inst. 16, 387 (1965).
${ }^{8}$ W. D. Kingery, H. K. Bowen, and D. R. Uhlmann, Introduction to Ceramics, 2nd ed. (Wiley, New York, 1976), p. 595.

${ }^{9}$ G. Shirane and S. Hoshino, J. Phys. Soc. Jpn. 6, 265 (1951).

${ }^{10}$ G. D. Yanson, E. N. Bindar, O. S. Maksimova, and E. Zh. Freidenfel'd, Zh. Neorg. Mater. 2, 1563 (1966).

${ }^{11}$ V. I. Andreeva, T. F. Limar, N. G. Kisel, D. S. Domenko, and Yu. N. Velichko, Kinet. Katal. 24, 1144 (1973).

${ }^{12}$ A. A. Dvernyakova, V. I. Stetsenko, and M. V. Sidorenko, Ukr. Khim. Zh. 51, 1136 (1985).

${ }^{13}$ S. Mrowec, Defects and Diffusion in Solids: An Introduction (Elsevier Scientific, Amsterdam, 1980).

${ }^{14}$ S. Ikegami, I. Ueda, and T. Nagata, J. Acoust. Soc. Am. 50, 1060 (1971). 